\title{
Noninfectious uveitis: strategies to optimize treatment compliance and adherence
}

REVIEW

Clinical Ophthalmology

18 August 2015

Number of times this article has been viewed

\author{
Rosa Dolz-Marco' \\ Roberto Gallego-Pinazo' \\ Manuel Díaz-Llopis ${ }^{2}$ \\ Emmett T Cunningham $\mathrm{Jr}^{3-6}$ \\ J Fernando Arévalo 7,8 \\ 'Unit of Macula, Department of \\ Ophthalmology, University and \\ Polytechnic Hospital La Fe, ${ }^{2}$ Faculty \\ of Medicine, University of Valencia, \\ Spain; ${ }^{3}$ Department of Ophthalmology, \\ California Pacific Medical Center, \\ San Francisco, ${ }^{4}$ Department of \\ Ophthalmology, Stanford University \\ School of Medicine, Stanford, ${ }^{5}$ The \\ Francis I Proctor Foundation, \\ University of California San Francisco \\ Medical Center, ${ }^{6}$ West Coast Retina \\ Medical Group, San Francisco, CA, \\ USA; ${ }^{7}$ Vitreoretina Division, King \\ Khaled Eye Specialist Hospital, \\ Riyadh, Saudi Arabia; ${ }^{8}$ Retina Division, \\ Wilmer Eye Institute, Johns Hopkins \\ University School of Medicine, \\ Baltimore, MD, USA
}

Correspondence: J Fernando Arévalo The Wilmer Eye Institute, Johns Hopkins University School of Medicine, $600 \mathrm{~N}$. Wolfe Street, Maumenee 708, Baltimore, MD 21287, USA

Tel + I 4432879554

Fax + I 4432875492

Email arevalojf@jhmi.edu

\begin{abstract}
Noninfectious uveitis includes a heterogenous group of sight-threatening ocular and systemic disorders. Significant progress has been made in the treatment of noninfectious uveitis in recent years, particularly with regard to the effective use of corticosteroids and non-corticosteroid immunosuppressive drugs, including biologic agents. All of these therapeutic approaches are limited, however, by any given patient's ability to comply with and adhere to their prescribed treatment. In fact, compliance and adherence are among the most important patient-related determinants of treatment success. We discuss strategies to optimize compliance and adherence.
\end{abstract}

Keywords: noninfectious uveitis, intraocular inflammation, immunosuppressive treatment, adherence, compliance, therapeutic failure

\section{Introduction}

Noninfectious uveitis includes a heterogenous group of sight-threatening immune-mediated ocular and systemic disorders. ${ }^{1,2}$ In some conditions, the inflammation is limited to the eye (primary ocular uveitis), whereas in other conditions, the uveitis is but one manifestation of a more complex systemic condition. ${ }^{3-5}$ Noninfectious uveitis may present at any age, but occurs most frequently in patients between 20 and 50 years of age. ${ }^{3-5}$ Uveitis may be either acute or chronic, and within these two broad categories, the course, duration, and severity can vary markedly. ${ }^{6}$ Therefore, treatment approaches needs to be tailored, to individual patients. ${ }^{6}$ The emergence of complicated, multidrug therapies for the management of intraocular inflammation requires that patients play a major role in treatment selection to ensure success. Treatment compliance and adherence, in particular, are among the most important patient-related determinants of treatment success. ${ }^{7}$

In order to discuss compliance and adherence, a clear and acceptable definition should be established. Although both terms are widely used as synonymous, they are not equivalent. In health care, treatment compliance is a "physician-centered" term, describing the degree to which patients properly follow the instructions or recommendations provided by their health care providers. ${ }^{8}$ Treatment adherence is a "patientcentered" term, referring to the extent to which a patient continues the agreed-upon mode of treatment under limited supervision when faced with conflicting demands. ${ }^{8}$ Use of either binary (noncompliance or compliance; non-adherence or adherence) or somewhat vague (good, poor, limited, etc) terms to describe patient compliance and adherence is commonplace. ${ }^{9,10}$

The purpose of the present review is to summarize the currently available methods for optimizing immunosuppressive treatment adherence in patients with noninfectious posterior uveitis. 


\section{Summary of therapeutic options for noninfectious uveitis}

Relevant advances in the treatment of noninfectious uveitis have taken place within the last decade. ${ }^{11}$ Although "classic" immunosuppressive drugs are still used most often, newer agents have been added to existing therapies. ${ }^{6,12,13}$ Table 1 summarizes both existing and emerging treatments for the management of noninfectious uveitis.

\section{Causes of compliance and adherence failure}

Noncompliance and non-adherence are complex and multidimensional health care issues. The World Health Organization classifies the risk factors for noncompliance and non-adherence into socioeconomic, patient-related, condition/disease-related, therapy/treatment-related, and health care system/worker-related risk factors. ${ }^{14}$

Socioeconomic factors have been studied across medical disciplines and can be related to either the patient or the caregiver. ${ }^{15-20}$ Patient-related socioeconomic factors can result in poor understanding of the disease or its treatment, in support of belief in unvalidated, belief-based treatment approaches, and limited access to care or treatment.

Table I Immunosuppressive drugs for the management of noninfectious Uveitis

\begin{tabular}{|c|c|c|}
\hline \multirow[t]{14}{*}{ Existing treatments } & \multicolumn{2}{|l|}{ Corticosteroids } \\
\hline & \multirow{2}{*}{$\begin{array}{l}\text { Leukocyte signaling } \\
\text { inhibitors }\end{array}$} & Cyclosporine A \\
\hline & & Tacrolimus \\
\hline & \multirow[t]{4}{*}{ Antimetabolites } & Azathioprine \\
\hline & & Methotrexate \\
\hline & & Mycophenolate \\
\hline & & (mofetil and sodium) \\
\hline & \multirow[t]{2}{*}{ Alkylating agents } & Cyclophosphamide \\
\hline & & Chlorambucil \\
\hline & \multirow{5}{*}{$\begin{array}{l}\text { Tumor necrosis } \\
\text { factor-alpha inhibitors }\end{array}$} & Etanercept \\
\hline & & Infliximab \\
\hline & & Adalimumab \\
\hline & & Golimumab \\
\hline & & Certolizumab \\
\hline \multirow[t]{12}{*}{ Emerging treatments } & \multicolumn{2}{|l|}{ Abatacept } \\
\hline & \multicolumn{2}{|l|}{ Alemtuzumab } \\
\hline & \multicolumn{2}{|l|}{ Anakinra } \\
\hline & \multicolumn{2}{|l|}{ Brodalumab } \\
\hline & \multicolumn{2}{|l|}{ Efalizumab } \\
\hline & \multicolumn{2}{|l|}{ Fezakinumab } \\
\hline & \multicolumn{2}{|l|}{ Gevokizumab } \\
\hline & \multicolumn{2}{|l|}{ Ixekizumab } \\
\hline & \multicolumn{2}{|l|}{ Rituximab } \\
\hline & \multicolumn{2}{|l|}{ Secukinumab } \\
\hline & \multicolumn{2}{|l|}{ Tocilizumab } \\
\hline & \multicolumn{2}{|l|}{ Ustekinumab } \\
\hline
\end{tabular}

Understandably, the views and responses of caregivers to these various issues have a major influence on outcomes. ${ }^{21-24}$ While addressing patient compliance and adherence, it is important for the caregiver to distinguish intentional noncompliance, based typically on fear or misconception, from unintentional noncompliance, which usually reflects a lack of understanding, busyness, or forgetfulness. ${ }^{25}$ For instance, a young patient might be reluctant to have oral steroids as these are associated with weight increase (intentional noncompliance); on the other hand, a patient might forget to have the medication when symptoms are improving (unintentional noncompliance).

\section{Measuring treatment compliance and adherence}

Noninfectious uveitis may occur as an isolated episode, or more frequently, as either chronic or recurrent disease. ${ }^{26}$ Although patients presenting with a single episode are typically compliant and adherent to prescribed treatments, both compliance and adherence are more difficult to achieve over time. While there is no gold-standard method for monitoring compliance and adherence to immunosuppressive therapies, several approaches are available including patient self-report, pill counting, refill rates, biological monitoring, and electronic monitoring. ${ }^{27-29}$ These approaches, like many others, are not ideal in routine clinical practice, because they have relevant limitations.

\section{Plasma levels}

Direct measurement of plasma drug levels is a widely available technique used for cyclosporine, tacrolimus, mycophenolate, and everolimus. ${ }^{27-29}$ Such pharmacokinetic monitoring is a reliable, albeit somewhat costly and cumbersome means of evaluating compliance and adherence to these treatments.

\section{Medication counting}

Both the uveitis specialist and the pharmacist can monitor adherence to treatment by counting pills or prescription refills, or by administering questionnaires to measure selfreported adherence. A medication diary or monitoring is another possibility, such as the "corticosteroid treatment card" currently recommended for patients prescribed systemic corticosteroids for more than 3 weeks in the UK. ${ }^{27-29}$ This particular strategy gives guidance to patients on minimizing adverse events and also provides data from the prescribing physician, characteristics of the drug as well as dosage and treatment duration. 


\section{Route of administration}

Optimizing the route of administration is helpful in order to guarantee adherence to the treatment. Intravenously administered drugs (infliximab, cyclophosphamide, chlorambucil, golimumab, abatacept, alemtuzumab, rituximab, and tocilizumab) are associated with an obvious verification of the time or administration. ${ }^{27-29}$ However, adherence to orally administered drugs (cyclosporine, tacrolimus, azathioprine, methotrexate, mycophenolate, and brodalumab) and selfadministered subcutaneous treatments (etanercept, adalimumab, certolizumab, abatacept, gevokizumab, anakinra, secukinumab, efalizumab, and ustekinumab) are completely dependent on the patient's compliance. ${ }^{27-29}$

\section{Medication dispensing and education}

Pharmacists play a key role in optimizing patient compliance and adherence when dispensing prescription medications, including those agents used to treat noninfectious uveitis. Each patient requires his or her own individualized approach. Issues that need to be typically discussed include timing and duration of dosing, whether oral agents should be taken with or without food, how to avoid and recognize treatment-related adverse events, and when and how to refill prescriptions..$^{27-29}$

\section{Evaluation of treatment-related side effects}

Use of immunosuppressive drugs can be associated with a number of treatment-related adverse events. ${ }^{6,12,13}$ A summary of the most commonly encountered treatment-related adverse events is presented in Table 2 .

\section{Strategies to promote compliance and adherence}

There is, in general, no clear consensus on how to optimize uveitis patients' compliance and adherence. The most commonly used interventions include providing clear instructions and encouraging an open and nonjudgmental dialogue regarding patient-encountered difficulties with compliance and adherence, simplifying the treatment regimen, and discussing with the patient specifics of their disease, the intended treatment goals, and the risks, benefits, and alternatives of various treatment options. ${ }^{30}$

The AIDES method attempts to summarize the key points for improving adherence to medications based on assessment (all medications), individualization (personalized regimen), documentation (written communication), education (continuing medical education), and supervision (continuous supervision of regimen). ${ }^{31}$
Table 2 Summary of the main adverse effects of the most frequently used existing immunosuppressive agents for the management of noninfectious posterior uveitis

\begin{tabular}{|c|c|}
\hline $\begin{array}{l}\text { Immunosuppressive } \\
\text { agent }\end{array}$ & Side effects \\
\hline Cyclosporine & $\begin{array}{l}\text { Nephrotoxicity, arterial hypertension, } \\
\text { gingivitis, hirsutism }\end{array}$ \\
\hline Tacrolimus & $\begin{array}{l}\text { Nephrotoxicity, neurologic symptoms, } \\
\text { gastrointestinal symptoms, hyperglycemia }\end{array}$ \\
\hline Azathioprine & $\begin{array}{l}\text { Hepatotoxicity, gastrointestinal } \\
\text { alterations, myelosuppression }\end{array}$ \\
\hline Methotrexate & Cytopenias, gastrointestinal symptoms \\
\hline Mycophenolate & Gastrointestinal symptoms \\
\hline Cyclophosphamide & $\begin{array}{l}\text { Hemorrhagic cystitis, myelosuppression, } \\
\text { infertility, neoplasms }\end{array}$ \\
\hline Chlorambucil & $\begin{array}{l}\text { Neurologic symptoms, gastrointestinal } \\
\text { symptoms, myelosuppression, neoplasms }\end{array}$ \\
\hline Etanercept & Acquired infections, reactivation of \\
\hline Infliximab & hepatitis $B$, reactivation of tuberculosis, \\
\hline Adalimumab & $\begin{array}{l}\text { drug-induced lupus, central nervous } \\
\text { system demyelinating disease, congestive } \\
\text { cardiac failure, neoplasms, uveitis } \\
\text { (etanercept) }\end{array}$ \\
\hline
\end{tabular}

Providing clear instructions to the patient

Research suggests that nearly $50 \%$ of patients leave the doctor's office with an incomplete understanding of what they have been told. ${ }^{30}$ Clear and simple treatment instructions should be provided both verbally and in writing. This means avoiding scientific terms and using colloquial language instead; it also means that health care providers should write information in short sentences and use brand names of medications, exact doses, and times of the day medications should be taken in their communications. The Centers for Disease Control and Prevention (CDC) Clear Communication Index is available on the Internet, ${ }^{32}$ and it contains guidelines and examples to enhance clarity and aid understanding. As appropriate and as authorized by the patient, the caregiver should encourage the presence of a companion or family member when treatment instructions are reviewed. Some patients choose to audio record such instructions. All patients should be given a telephone number to call for clarifications (if needed).

\section{Modifying patient misconceptions}

Addressing a patient's misconceptions can be difficult and time-consuming, but it is essential in order to avoid intentional noncompliance and non-adherence. Health care providers should take time to describe the condition, the causes and risks of vision loss, and the risks, benefits, and alternatives to treatment. Health care providers should specifically ask what concerns the patient most about their condition and 
whether they envision any problems or issues related to the recommended therapy. ${ }^{27-29}$

\section{Enhancing patient communication}

Encouraging an open and nonjudgmental dialogue with patients is essential to promote compliance and adherence. Avoiding general assumptions and highly technical language is also of paramount importance. Asking each patient to summarize the instructions as provided and whether they have any concerns regarding their ability to adhere to the recommended treatment is also essential. ${ }^{27-29}$

\section{Simplifying the treatment regimen}

Changing the route of administrations may be an effective way to enhance adherence and compliance. A sustainedrelease corticosteroid injection may be preferable to frequent drops, for example. The most widely used sustained-release corticosteroid preparations include depot of triamcinolone acetonide ${ }^{33-37}$ and dexamethasone intravitreal implant. ${ }^{38}$ Similarly, combined formulations are available for several intraocular pressure-lowering medications. In addition, there are a number of aids available to help patients organize their medications (medication boxes), remember dosing times (alarms), and track treatments over time (smartphone applications). ${ }^{27-29}$

\section{Evaluating compliance and adherence}

At each visit, health care providers are advised to ask patients to summarize the name, dose, and dosing schedule for each treatment. For complex treatment regimens, compliance and adherence are also enhanced by encouraging the use of a diary and/or treatment list that can be readily reviewed and updated. ${ }^{27-29}$

\section{Discussion}

Noninfectious uveitis represents a heterogenous group of inflammatory disorders, the treatment of which if often challenging for both the patient and the physician. Success with complex, multi-agent treatment strategies requires close patient-physician collaboration to optimize patient understanding, compliance, and adherence. Pharmacists also play a related and important role. Several techniques are available to increase both compliance and adherence in patients with ocular inflammation.

\section{Disclosure}

The authors report no conflicts of interest in this work.

\section{References}

1. Suttorp-Schulten MS, Rothova A. The possible impact of uveitis in blindness: a literature survey. Br J Ophthalmol. 1996;80(9):844-848.

2. de Smet MD, Taylor SR, Bodaghi B, et al. Understanding uveitis: the impact of research on visual outcomes. Prog Retin Eye Res. 2011;30(6): 452-470.

3. Smit RL, Baarsma GS. Epidemiology of uveitis. Curr Opin Ophthalmol. 1995;6(3):57-61.

4. London NJ, Rathinam SR, Cunningham ET Jr. The epidemiology of uveitis in developing countries. Int Ophthalmol Clin. 2010;50(2): $1-17$.

5. Miserocchi E, Fogliato G, Modorati G, Bandello F. Review on the worldwide epidemiology of uveitis. Eur J Ophthalmol. 2013;23(5):705-717.

6. Gallego-Pinazo R, Dolz-Marco R, Martínez-Castillo S, Arévalo JF, Díaz-Llopis M. Update on the principles and novel local and systemic therapies for the treatment of non-infectious uveitis. Inflamm Allergy Drug Targets. 2013;12(1):38-45.

7. Cunningham ET Jr. Exogenous factors influencing endogenous inflammation: what can patients do to improve control of their own uveitis? Br J Ophthalmol. 2010;94(7):813-814.

8. Jin J, Sklar GE, Min Sen Oh V, Chuen Li S. Factors affecting therapeutic compliance: A review from the patient's perspective. Ther Clin Risk Manag. 2008;4(1):269-286.

9. Budenz DL. A clinician's guide to the assessment and management of nonadherence in glaucoma. Ophthalmology. 2009;116(11 Suppl):S43-S47.

10. Osterberg L, Blaschke T. Adherence to medication. N Engl J Med. 2005; 353(5):487-497.

11. Lee RW, Dick AD. Current concepts and future directions in the pathogenesis and treatment of non-infectious intraocular inflammation. Eye (Lond). 2012;26(1):17-28.

12. Mikhail M, Sallam A. Novel intraocular therapy in non-infectious uveitis of the posterior segment of the eye. Med Hypothesis Discov Innov Ophthalmol. 2013;2(4):113-120.

13. Agrawal R, Iyer J, Connolly J, Iwata D, Teoh S. Cytokines and biologics in non-infectious autoimmune uveitis: bench to bedside. Indian J Ophthalmol. 2014;62(1):74-81.

14. Sabaté E. Adherence to Long-term Therapies: Evidence for Action. Geneva: World Health Organisation; 2003.

15. De Geest S, Abraham I, Gemoets H, Evers G. Development of the long-term medication behaviour self-efficacy scale: qualitative study for item development. $J$ Adv Nurs. 1994;19(2):233-238.

16. De Geest S, Borgermans L, Gemoets H, et al. Incidence, determinants, and consequences of subclinical noncompliance with immunosuppressive therapy in renal transplant recipients. Transplantation. 1995;59(3): 340-347.

17. Siegal B, Greenstein SM. Profiles of noncompliance in patients with a functioning renal transplant: a multicenter study. Compliance Study Group. Transplant Proc. 1999;31(1-2):1326-1327.

18. Siegal B, Greenstein S. Compliance and noncompliance in kidney transplant patients: cues for transplant coordinators. J Transpl Coord. 1999; 9(2):104-108

19. Ghods AJ, Nasrollahzadeh D, Argani H. Risk factors for noncompliance to immunosuppressive medications in renal transplant recipients. Transplant Proc. 2003;35(7):2609-2611.

20. Senabre-Gallego JM, Rosas-Gómez de Salazar J, Santos-Soler G, et al. [Duration of treatment with etanercept and motives for discontinuation in a cohort of patients with rheumatic disease]. Reumatol Clin. 2011;7(6): 385-388. Spanish.

21. Horne R. Patients' beliefs about treatment: the hidden determinant of treatment outcome? J Psychosom Res. 1999;47(6):491-495.

22. Pinzone HA, Carlson BW, Kotses H, Creer TL. Prediction of asthma episodes in children using peak expiratory flow rates, medication compliance, and exercise data. Ann Allergy. 1991;67(5):481-486.

23. Shih MH, Tsai CH. [Factors associated with adherence to immunosuppressive therapy among transplant recipients]. Hu Li Za Zhi. 2014; 61(4):21-25. Chinese. 
24. Miller WR, Rollnick S. The effectiveness and ineffectiveness of complex behavioral interventions: impact of treatment fidelity. Contemp Clin Trials. 2014;37(2):234-241.

25. Hugtenburg JG, Timmers L, Elders PJ, Vervloet M, van Dijk L. Definitions, variants, and causes of nonadherence with medication: a challenge for tailored interventions. Patient Prefer Adherence. 2013;7:675-682.

26. Okada AA, Jabs DA. The standardization of uveitis nomenclature project: the future is here. JAMA Ophthalmol. 2013;131(6):787-789.

27. Dayer L, Heldenbrand S, Anderson P, Gubbins PO, Martin BC. Smartphone medication adherence apps: potential benefits to patients and providers. J Am Pharm Assoc (2003). 2013;53(2):172-181.

28. Rawlind MD, Breckenridge AM, Wood SM, Waller PC, Arlett P. Using long-term systemic corticosteroids safely. In: Rawlins MD, editor. Current Problems in Pharmacovigilance. 23rd Vol. London: Committee on Safety in Medicines; 1997.

29. Burgess P, O'Dowd J, Kumar N. 'Steroid treatment card' compliance is suboptimal but can be improved. Eye (Lond). 2010;24(8):1409-1410.

30. Atreja A, Bellam N, Levy SR. Strategies to enhance patient adherence: making it simple. Med Gen Med. 2005;7(1):4.

31. Aronson JK. Compliance, concordance, adherence. Br J Clin Pharmacol. 2007;63(4):383-384.

32. The CDC Clear Communication Index. Atlanta, GA: Centers for Disease Control and Prevention [updated August 11, 2014]. Available from: http://www.cdc.gov/ccindex/. Accessed January 15, 2015.
33. Tanner V, Kanski JJ, Frith PA. Posterior sub-Tenon's triamcinolone injections in the treatment of uveitis. Eye (Lond). 1998;12(Pt 4):679-685.

34. Ferrante P, Ramsey A, Bunce C, Lightman S. Clinical trial to compare efficacy and side-effects of injection of posterior sub-Tenon triamcinolone versus orbital floor methylprednisolone in the management of posterior uveitis. Clin Experiment Ophthalmol. 2004;32(6):563-568.

35. Ohguro N, Yamanaka E, Otori Y, Saishin Y, Tano Y. Repeated intravitreal triamcinolone injections in Behçet disease that is resistant to conventional therapy: one-year results. Am J Ophthalmol. 2006;141(1):218-220.

36. Cunningham MA, Edelman JL, Kaushal S. Intravitreal steroids for macular edema: the past, the present, and the future. Surv Ophthalmol. 2008;53(2): $139-149$.

37. Lasave AF, Zeballos DG, El-Haig WM, Díaz-Llopis M, Salom D, Arevalo JF. Short-term results of a single intravitreal bevacizumab (avastin) injection versus a single intravitreal triamcinolone acetonide (kenacort) injection for the management of refractory noninfectious uveitic cystoid macular edema. Ocul Immunol Inflamm. 2009;17(6): 423-430.

38. Lowder C, Belfort R Jr, Lightman S, et al; Ozurdex HURON Study Group. Dexamethasone intravitreal implant for noninfectious intermediate or posterior uveitis. Arch Ophthalmol. 2011;129(5):545-553.
Clinical Ophthalmology

\section{Publish your work in this journal}

Clinical Ophthalmology is an international, peer-reviewed journal covering all subspecialties within ophthalmology. Key topics include: Optometry; Visual science; Pharmacology and drug therapy in eye diseases; Basic Sciences; Primary and Secondary eye care; Patien Safety and Quality of Care Improvements. This journal is indexed on

Submit your manuscript here: http://www.dovepress.com/clinical-ophthalmology-journal

\section{Dovepress}

PubMed Central and CAS, and is the official journal of The Society of Clinical Ophthalmology (SCO). The manuscript management system is completely online and includes a very quick and fair peer-review system, which is all easy to use. Visit http://www.dovepress.com/ testimonials.php to read real quotes from published authors. 